\title{
Gene mining-based identification of aldo- keto reductases for highly stereoselective reduction of bulky ketones
}

\author{
Chen Liang ${ }^{1}$, Yao $\mathrm{Nie}^{1 *}$, Xiaoqing $\mathrm{Mu}^{1}$ and Yan $\mathrm{Xu}^{1,2}$
}

\begin{abstract}
Background: Aldo-keto reductase (AKR) or alcohol dehydrogenases (ADH)-mediated stereoselective reduction of prochiral carbonyl compounds is an efficient way of preparing single enantiomers of chiral alcohols. However, steric hindrance of substrate affects the catalytic performance of enzymes. The present study aims to discover and identify AKRs/ADHs capable of catalyzing highly stereoselective reduction of sterically hindered ketones.

Results: Five AKRs from different microorganisms (CaCR, ScCR, KmCR, CPR-C1, and CPR-C2) were identified through gene mining, and overexpressed in recombinant Escherichia coli BL21(DE3). The specific activity and stereoselectivity of the AKRs were further evaluated towards various ketoesters and heterocyclic ketones, which are sterically bulky and are valuable in industrial applications. Each purified enzyme exhibited catalytic activity to one or more of the tested substrates. Among the enzymes, ScCR showed a broader substrate spectrum compared to the others. Regarding $K_{m}$ values related to substrate association, we also provided insights into the specificity and preference of certain enzymes. Consequently, enantiopure ( $R$ )-methyl mandelate, ethyl $(R)$-mandelate, ethyl $(R)$-2-hydroxy-4-phenylbutyrate, and (S)-N-benzyl-3-pyrrolidinol (>99\%e.e.) were obtained through the identified AKRs.
\end{abstract}

Conclusion: The stereospecific AKRs were obtained through gene mining, which possesses the potential for application in the preparation of important optically active alcohols.

Keywords: Aldo-keto reductase, Carbonyl compound, Gene mining, Stereoselectivity, Substrate specificity

\section{Background}

Optically active alcohols have been recognized as key chiral intermediates for synthesizing fine chemicals and pharmaceuticals (Schoemaker et al. 2003; Zhao et al. 2017). Aldo-keto reductase (AKR) or alcohol dehydrogenase (ADH)-mediated stereoselective reduction of prochiral carbonyl compounds is an efficient way of preparing single enantiomers of chiral alcohols due to the high chemo-, enantio-, and regioselectivity of the enzymes (Ma et al. 2013). However, the majority of prochiral ketones used in industrial applications are structurally complex. These include ketoesters and

\footnotetext{
*Correspondence: ynie@jiangnan.edu.cn

1 School of Biotechnology and Key Laboratory of Industrial Biotechnology of Ministry of Education, Jiangnan University, 1800 Lihu Road,

Wuxi 214122, China

Full list of author information is available at the end of the article
}

heterocyclic ketones bearing bulky substituents, such as ethyl $(R)$-2-hydroxy-4-phenylbutyrate [(R)-HPBE], a key precursor for the preparation of an anti-hypertension drug, the angiotensin-converting enzyme (ACE) inhibitor (de Lacerda et al. 2006), and (S)- $N$-benzyl-3-pyrrolidinol, an important intermediate for the preparation of antitumor and anesthetic drugs (Kizaki et al. 2008). Substrate size-induced deficiency of enzyme activity is still a challenge for the enzymatic reduction of ketones. Therefore, it is necessary to develop suitable enzymes for substrates with bulky groups, for the production of corresponding chiral alcohols with high optical purity (Athanasiou et al. 2001).

For the discovery and identification of useful enzymes, bioinformatics analysis-based search from databases can be helpful in increasing the possibility and efficiency of finding candidate ideal biocatalysts (Kaluzna et al. 
2004). Gene mining, a method through which homologous proteins are searched from a gene database using known enzymes as the template, is a promising approach (Wang et al. 2011). Through this method, various carbonyl reductases and AKRs exhibiting catalytic activities towards various carbonyl substrates have been discovered from the genome of Candida parapsilosis (Guo et al. 2014; Nie et al. 2011).

Here, the carbonyl-reducing enzymes from C. albicans (CaCR), Saccharomyces cerevisiae (ScCR), Kluyveromyces marxianus (KmCR), and C. parapsilosis (CPR-C1, CPR$\mathrm{C} 2$ ) were identified through gene mining. These enzymes are expected to address the problem of enzymatic reactions with bulky substrates such as ketoesters and heterocyclic ketones, which are precursors for synthesizing key intermediates of important pharmaceuticals (Table 1). The biocatalytic properties of the newly identified enzymes towards the tested carbonyl substrates were also evaluated.

\section{Methods}

\section{Chemicals and strains}

Ketone substrates such as, methyl benzoylformate (1a), ethyl benzoylformate (2a), ethyl 2-oxo-4-phenylbutyrate (3a), ethyl benzoylacetate (4a), 1-benzyl-3-pyrrolidinone (5a), and the enantiomers of corresponding chiral alcohols, methyl 2-hydroxy-2-phenylacetate (1b), ethyl mandelate (2b), ethyl 2-hydroxy-4-phenylbutyrate (3b), 3-hydroxy-3-phenylpropionate (4b), and $\mathrm{N}$-benzyl3-pyrrolidinol (5b), were obtained from J\&K Chemical
(Beijing, China). The cofactors (NADH and NADPH) were purchased from Solarbio (Beijing, China). The organic solvents used for product analysis by high-performance liquid chromatography (HPLC) were purchased from Tedia (Anhui, China).

Candida albicans CICC 31283, S. cerevisiae CICC1002, and K. marxianus CICC 1609 from the China Center of Industrial Culture Collection (Beijing, China) were used to obtain the genes encoding $\mathrm{CaCR}, \mathrm{ScCR}$, and $\mathrm{KmCR}$, respectively. C. parapsilosis CCTCC M203011 from the China Center of Typical Culture Collection (Wuhan, China) was applied to obtain the genes encoding CPR$\mathrm{C} 1$ and CPR-C2. Escherichia coli BL21(DE3) was adopted for expressing AKRs. The plasmid pET28a was purchased from Novagen (USA). Restriction endonucleases and PrimeSTAR ${ }^{\circledR}$ DNA polymerase (Premix) were obtained from Takara (Dalian, China).

\section{Homologous protein-searching analysis}

The BLAST tool at NCBI (https://blast.ncbi.nlm.nih.gov/ Blast.cgi) was used to discover potential AKRs for bulky substrates, with the CaAKR amino acid sequence (GenBank Accession No. XP_711680.1) as the searching template, which has been identified to reduce bulky ketones (Wang et al. 2015). ClustalX software and Espript 3.0 were used for multiple sequence alignment.

\section{Expression of AKRs in recombinant E. coli}

The AKR genes were amplified from extracted genomic DNAs of C. albicans, S. cerevisiae, $K$. marxianus, and $C$.

Table 1 Substrates and applications of the corresponding alcohols

Entry
(R)-1b, a precursor of semi-synthetic penicillins, cephalosporins,
vasodilators, fungicides, and sedatives


parapsilosis using the restriction sites-involved primer pairs synthesized according to the gene sequences of potential AKRs, respectively (Additional file 1: Table S1). By digestion with the corresponding restriction endonucleases, the resulting DNA fragments were inserted into the vector $\mathrm{pET} 28 \mathrm{a}$ for expression. The recombinant plasmids, pET-28a-CaCR, pET-28a-ScCR, pET-28a-KmCR, pET-28a-CPR-C1, and pET-28a-CPR-C2, were transformed individually into the expression host cells of $E$. coli BL21(DE3). The transformants were incubated in the LB medium comprising $50 \mu \mathrm{g} \mathrm{mL}^{-1}$ kanamycin at $37{ }^{\circ} \mathrm{C}$ with shaking at $200 \mathrm{rpm}$.

The expression of target recombinant proteins was induced with $1 \mathrm{mM}$ IPTG when the biomass of the culture reached approximately $0.6-0.8$ in $\mathrm{OD}_{600}$, followed by further incubation at $17{ }^{\circ} \mathrm{C}$ for $14-16 \mathrm{~h}$.

\section{Purification of recombinant enzymes}

Through centrifugation at $7104 \times g$ and $4{ }^{\circ} \mathrm{C}$ for $20 \mathrm{~min}$, the harvested cells were washed twice with saline. After resuspension in the binding buffer $(500 \mathrm{mM} \mathrm{NaCl}$, $20 \mathrm{mM}$ imidazole, $20 \mathrm{mM}$ Tris/ $\mathrm{HCl}$, and $\mathrm{pH}$ 8.0), the cells were disrupted by an Vibra-Cell ${ }^{\mathrm{TM}}$ Ultrasonic Liquid Processor VCX750 (Sonic, USA). Through centrifugation at $26,000 \times g$ and $4{ }^{\circ} \mathrm{C}$ for $40 \mathrm{~min}$, the supernatant was collected and then purified by Ni-NTA affinity chromatography on AKTA purifier 10 (GE Healthcare, USA). The enzymes were obtained with an elution buffer $(500 \mathrm{mM}$ $\mathrm{NaCl}, 150 \mathrm{mM}$ imidazole, $20 \mathrm{mM}$ Tris/ $\mathrm{HCl}$, and $\mathrm{pH}$ 8.0). The collected protein fractions were dialyzed against the buffer $(500 \mathrm{mM} \mathrm{NaCl}, 20 \mathrm{mM}$ Tris/ $\mathrm{HCl}$, and $\mathrm{pH} 8.0)$ at $4{ }^{\circ} \mathrm{C}$ for $12 \mathrm{~h}$. The molecular weight and purity of the enzymes were determined through SDS-PAGE with a $10 \%$ polyacrylamide gel.

\section{Enzyme assay}

By recording the decline of the absorbance of the cofactor at $340 \mathrm{~nm}$, enzyme activity was determined in the standard reaction mixture $(100 \mu \mathrm{L})$ consisting of sodium phosphate buffer $(0.1 \mathrm{M}, \mathrm{pH}$ 6.5), $0.5 \mathrm{mM} \mathrm{NAD}(\mathrm{P}) \mathrm{H}$, $5 \mathrm{mM}$ substrate, and an appropriate amount of purified enzyme. Protein concentration was measured through Bradford assay with bovine serum albumin (BSA) as the standard. One unit of AKR activity was defined as the amount of enzyme demanded to catalyze the oxidation of $1 \mu \mathrm{mol}$ cofactor (NADH or NADPH) per minute under the given conditions.

\section{Measurement of kinetic parameters}

To determine the Michaelis-Menten kinetic parameters of the enzymes, the initial velocities of enzymatic reactions were measured at different concentrations of each substrate $(0.05-4 \mathrm{mM})$, with the cofactor at saturated concentrations. Tetrahydrofuran $(1 \% \mathrm{v} / \mathrm{v})$ was used as the cosolvent for the dissolution of carbonyl substrates. Apparent kinetic parameters of the enzymes were calculated from Lineweaver-Burk double-reciprocal plot.

\section{Asymmetric reductions and analytical methods}

The reaction mixture in $2 \mathrm{~mL}$ was composed of sodium phosphate buffer (0.1 M, pH 6.5), $0.5 \mathrm{mM} \operatorname{NAD}(\mathrm{P})$ $\mathrm{H}, 1 \mathrm{~g} \mathrm{~L}^{-1}$ substrate, isopropanol $(0.5 \% \mathrm{v} / \mathrm{v})$, and an appropriate amount of purified enzyme. After reaction with shaking at $30{ }^{\circ} \mathrm{C}$ for $8 \mathrm{~h}$, the resulting mixture was extracted using ethyl acetate with vigorous mixing. Then, the organic layer of the mixture was filtered through a $0.22-\mu \mathrm{m}$ syringe filter (Troody Technology, China). Optical purities of the products were analyzed through HPLC (Table 2).

\section{Results and discussion Discovery of potential AKRs}

A recombinant expressing an NADH-dependent AKR from C. albicans XP1463 CaAKR has been reported. The enzyme CaAKR exhibits high catalytic activity towards bulky ketones, such as N,N-2-dimethyl3-oxo-3-(2-thienyl)-1-propanine. In addition, CaAKR displayed high enantioselectivity towards most of the tested bulky ketones with the optical purity of 99\%e.e. The gene mining approach was adopted to find potential enzymes that can catalyze the reduction of bulky ketones using the amino acid sequence of CaAKR as

Table 2 Analytical methods of enantiomers of chiral alcohols

\begin{tabular}{lllll}
\hline Alcohols & HPLC condition & \multicolumn{2}{c}{ Retention time (min) } & References \\
& & $\mathbf{t}_{\boldsymbol{R}}$ & $\mathbf{t s}$ & \\
\hline$(R, S)-1 \mathrm{~b}$ & $\mathrm{OB}-\mathrm{H}, 210 \mathrm{~nm}$, hexane:2-propanol =88:12 & 15.2 & 16.2 & Guo et al. (2010) \\
$(R, S)-2 \mathrm{~b}$ & $\mathrm{OD}-\mathrm{H}, 210 \mathrm{~nm}$, hexane:2-propanol =97:3 & 23.9 & 12.3 & Kasprzak et al. (2016) \\
$(R, S)-3 \mathrm{~b}$ & $\mathrm{OD}-\mathrm{H}, 210 \mathrm{~nm}$, hexane:2-propanol $=19: 1$ & 13.1 & 9.0 & Nikaido et al. (1992) \\
$(R, S)-4 \mathrm{~b}$ & $\mathrm{OB}-\mathrm{H}, 220 \mathrm{~nm}$, hexane:2-propanol =9:1 & 10.7 & 8.5 & Ou et al. (2011) \\
$(R, S)-5 \mathrm{~b}$ & $\mathrm{OB}-\mathrm{H}, 220 \mathrm{~nm}$, hexane:2-propanol =19:1 & 7.9 & 10.8 & Yamada-Onodera et al. (2007) \\
\hline
\end{tabular}


a probe (Wang et al. 2015). About 80 proteins sharing $42-99 \%$ of identity with the amino acid sequence of CaAKR were searched. Among them, more than $2 / 3$ of the proteins share less than $50 \%$ of identity. Considering the difference of sequence identity and the practical feasibility and availability of microorganisms as the enzyme sources, five proteins were finally selected as the candidates of suitable biocatalysts towards the tested substrates. These five proteins sharing $42-99 \%$ of identity with the amino acid sequence of the template, CaCR (Genbank Accession No. KGR02412.1), CPR-C1 (Genbank Accession No. AB084516.1), ScCR (Genbank Accession No. AJU60509.1), KmCR (Genbank Accession No. BAO41772.1), and CPR-C2 (Genbank Accession No. AB084515.1) were selected from GenBank database using BLAST (Table 3). From the multiple sequence alignment analysis of these polypeptides (Fig. 1), it was observed that the selected proteins possess a classic Rossmann-fold structure containing the catalytic tetrad $\mathrm{D}-\mathrm{X}_{4}-\mathrm{Y}-\mathrm{X}_{\mathrm{n}}-\mathrm{K}-\mathrm{X}_{\mathrm{n}}-\mathrm{H}$ (Jez et al. 1997). In addition, the signature sequences (PROSITE Accession No.: PS00798 and PS00062) and the putative active site signature sequence (PROSITE Accession No.: PS00063) of AKR family were conserved in these homologous sequences, suggesting that the selected proteins can be classified as AKRs. The phylogenetic tree was constructed with other AKRs from various microbes to understand the homologous relevance (Additional file 1: Fig. S1). The AKRs involved in the phylogenetic tree were listed at the AKR homepage (http://www.med.upenn.edu/akr/). Phylogenetic analysis showed that these five enzymes are closely related and belong to the AKR3 subfamily. Nevertheless, some residues were not strictly conserved in the IPKS motif, which participates in cofactor binding, indicating the differences in their catalytic properties, such as cofactor affinity and substrate specificity.

\section{Protein expression and purification}

The DNA fragments encoding the newly identified proteins were amplified and inserted into the expression

\section{Table 3 Selected proteins from GenBank by BLAST against CaAKR}

\begin{tabular}{lllll}
\hline Enzyme & GenBank ID & Source & Identity (\%) & $\begin{array}{l}\text { Theoretical } \\
\text { molecular } \\
\text { weight (Da) }\end{array}$ \\
\hline CaCR & KGR02412.1 & C. albicans & 99 & 35,260 \\
CPR-C2 & AB084516.1 & C. parapsilosis & 65 & 34,650 \\
ScCR & AJU60509.1 & S. cerevisiae & 46 & 35,625 \\
KmCR & BAO41772.1 & K. marxianus & 45 & 35,401 \\
CPR-C1 & AB084515.1 & C.parapsilosis & 42 & 34,491 \\
\hline
\end{tabular}

vector pET-28a, and the recombinant plasmids, pET28a-CaCR, pET-28a-ScCR, pET-28a-KmCR, pET28a-CPR-C1, and pET-28a-CPR-C2 were independently transformed into the host cells of $E$. coli BL21(DE3). Consequently, the recombinant AKRs were actively expressed from the transformants (Fig. 2a). Next, the C-terminal His-tagged recombinant enzymes were purified through Ni-NTA affinity chromatography. The purified $\mathrm{CaCR}$, ScCR, KmCR, CPR-C1, and CPR-C2 exhibited a single band around $35 \mathrm{kDa}$ upon analysis through SDS-PAGE, correctly corresponding to their theoretically calculated molecular weights (Fig. 2b).

\section{Substrate specificity}

The capability of the recombinant AKRs in catalyzing stereospecific reduction of bulky carbonyl compounds was investigated using various substrates, including ketoesters and heterocyclic ketones. NADPH was used as the coenzyme (specific activities of the enzymes with $\mathrm{NADH}$ are shown in Fig. S2 in Additional file 1). As shown in Fig. 3, the recombinant enzymes exhibited different levels of activity in catalyzing the reduction of various substrates. In general, the enzymes were more suitable for reducing $\alpha$-ketoesters of relatively modest size, especially $2 \mathrm{a}$. With $2 \mathrm{a}$ as the substrate, the enzymes all exhibited their highest activities at pH $7.0(0.1 \mathrm{M}$ sodium phosphate buffer) (Additional file 1: Fig. S3). Among the enzymes, ScCR showed a broader substrate spectrum compared to the other enzymes, being active towards substrates $1 \mathrm{a}-4 \mathrm{a}$. The enzymes generally exhibited lower activity towards $5 \mathrm{a}$ when compared with other substrates, which may be due to the chemical structure of $5 \mathrm{a}$, comprising benzyl and pyrrole groups, which is different from the other ketoester substrates.

Furthermore, the affinity and catalytic efficiency of the enzymes towards the tested substrates were evaluated by measuring the corresponding Michaelis-Menten kinetic parameters (Fig. 4). ScCR and CPR-C1 both showed lower $K_{\mathrm{m}}$ values towards $1 \mathrm{a}(0.23$ and $0.14 \mathrm{mM})$ than towards $2 \mathrm{a}(0.75$ and $0.23 \mathrm{mM})$, indicating that the affinity of the enzyme towards the substrate is affected by the length of the side chain neighboring the carbonyl group. For 3a, with a phenylethyl next to the carbonyl group, the $K_{\mathrm{m}}$ value of $\mathrm{KmCR}$ was $0.85 \mathrm{mM}$, the lowest among the test enzymes. In addition, for both $1 \mathrm{a}$ and 2a, CPR-C1 exhibited higher $k_{\text {cat }} / K_{\mathrm{m}}$ values (1.26 and $\left.1.25 \mathrm{mM}^{-1} \mathrm{~s}^{-1}\right)$ than ScCR $\left(0.92\right.$ and $\left.0.53 \mathrm{mM}^{-1} \mathrm{~s}^{-1}\right)$, indicating that $\mathrm{CPR}-\mathrm{C} 1$ is more suitable for the reduction of $\alpha$-ketoesters. Among the enzymes, ScCR was active towards four ketoesters, in which its affinity towards $\alpha$-ketoesters followed the trend of change in the length of sidechain. Otherwise, ScCR showed a higher affinity towards $\beta$-ketoester (4a) than towards $\alpha$-ketoester (3a), 


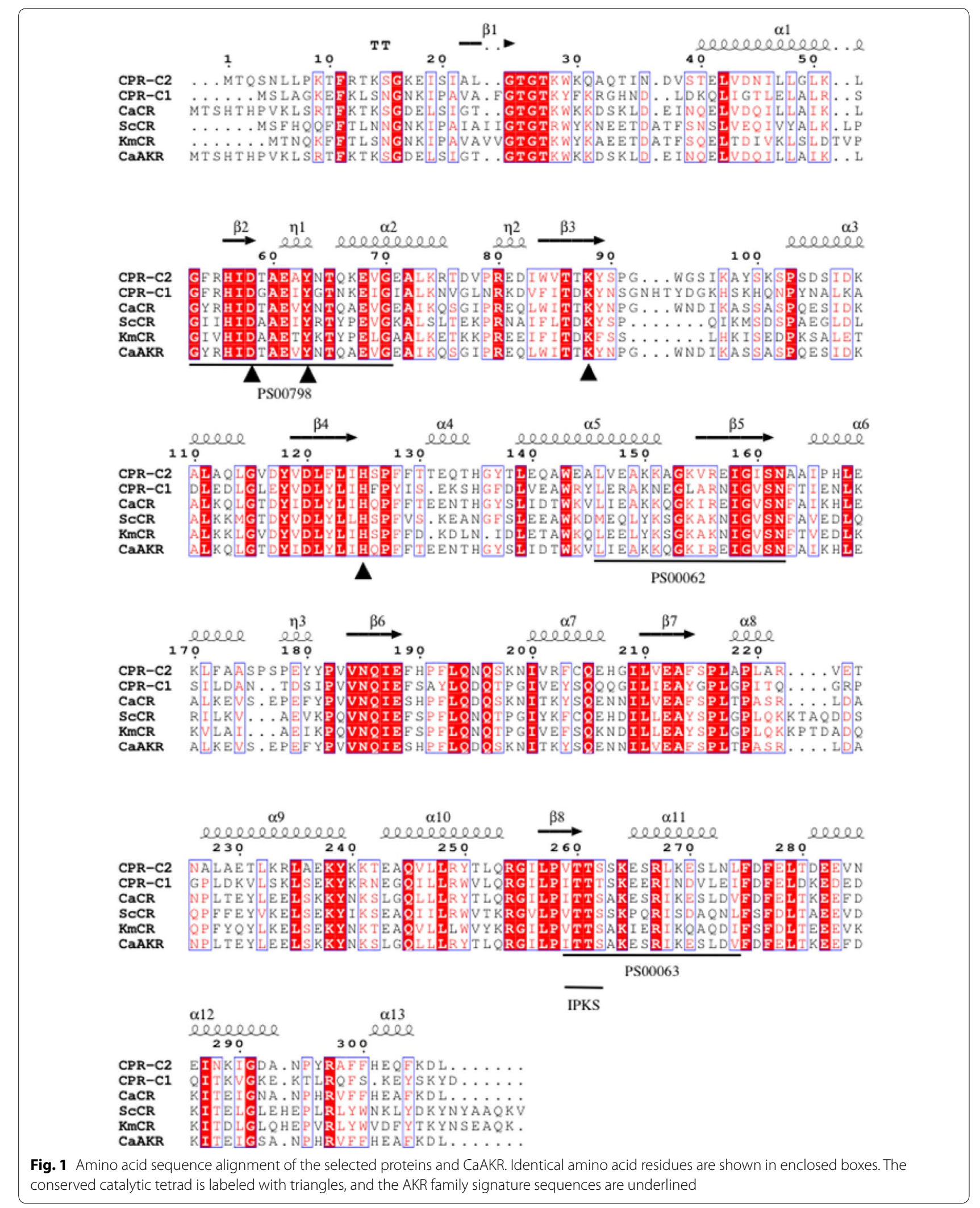



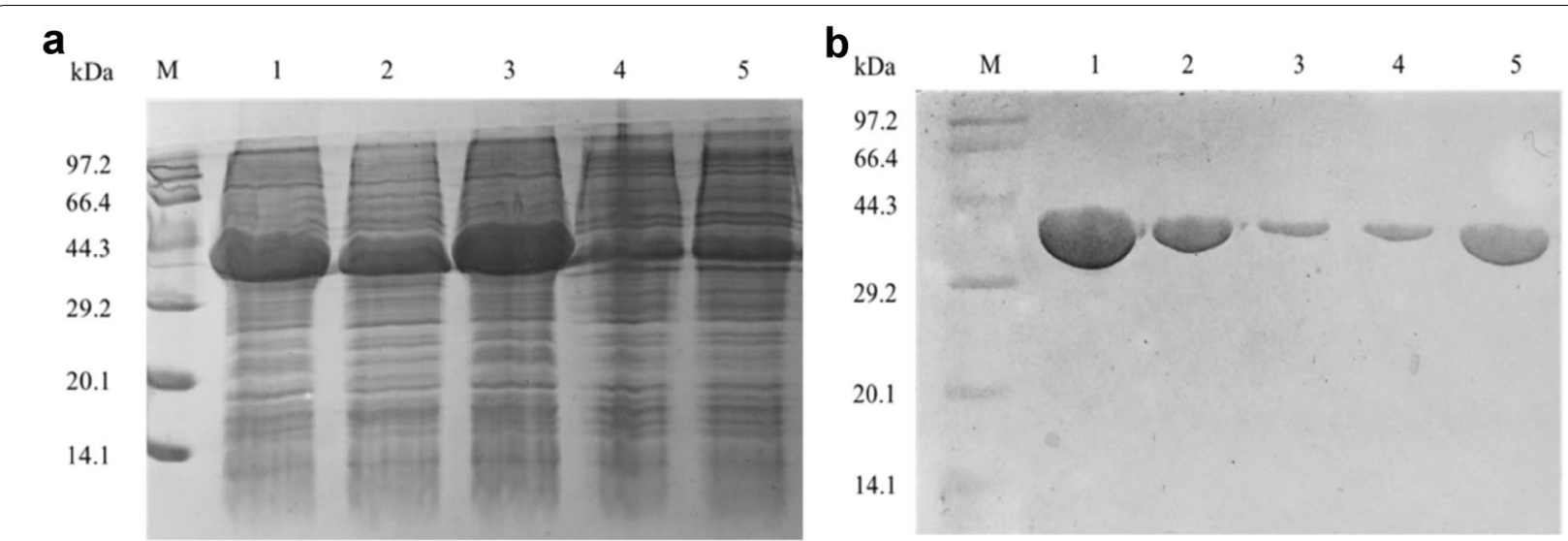

Fig. 2 SDS-PAGE analysis of a expression and b purification of the enzymes. Line M, molecular weight standard; lane 1, CaCR; lane 2, ScCR; lane 3, KmCR; lane 4, CPR-C1; lane 5, CPR-C2

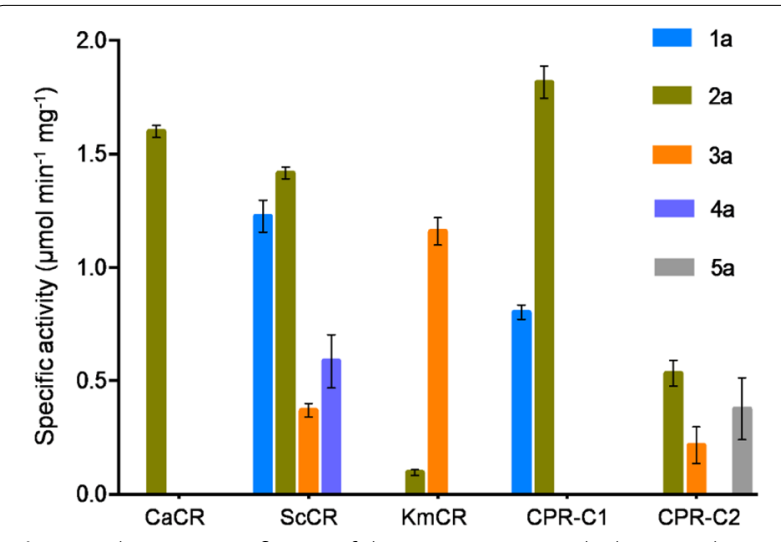

Fig. 3 Substrate specificities of the enzymes towards the tested carbonyl substrates, including (1a) methyl benzoylformate, (2a) ethyl benzoylformate, (3a) ethyl 2-oxo-4-phenylbutyrate, (4a) ethyl benzoylacetate, and (5a) 1-benzyl-3-pyrrolidinone. The reaction mixture consisted of $0.1 \mathrm{M}$ sodium phosphate buffer ( $\mathrm{pH} 6.5), 0.5 \mathrm{mM}$ $\mathrm{NADPH}, 5 \mathrm{mM}$ substrate, and the appropriate enzyme in a total volume of $100 \mu \mathrm{L}$. The experiments were carried out in triplicate, and the error bars represent the standard error of the mean

despite the similarity in chemical structure of these two substrates. Among the test enzymes, only CPR-C2 exhibited affinity towards $5 \mathrm{a}$, indicating the distinct conformation of the substrate-binding pocket of this enzyme.

\section{Enantioselectivity}

The enantioselectivity of an enzyme is important for the production of enantiopure alcohols. The configuration and the corresponding optical purity of a chiral alcohol determine its value in industrial application. Therefore, the enantioselectivities of the recombinant enzymes catalyzing asymmetric reduction were evaluated towards substrates $1 \mathrm{a}-5 \mathrm{a}$. The tested substrates were converted to the chiral alcohols correspondingly, in line with the demand of stereo-configuration for applications (Fig. 5). The stereospecific reduction of prochiral carbonyl compounds catalyzed by the identified enzymes was supposed to follow the Prelog's rule, leading to the synthesis of enantiopure alcohols $[1 \mathrm{~b}-3 \mathrm{~b}$ in $(R)$-configuration and $5 \mathrm{~b}$ in $(S)$-configuration]. Notably, $(S)$-5b with excellent optical purity (>99\%e.e.) was obtained from CPR-C2-catalyzed asymmetric reduction of $5 \mathrm{a}$ with benzyl and pyrrole groups, indicating that this substrate may fit well to the active site of the enzyme.

\section{Conclusions}

Stereospecific AKRs were discovered through gene mining. The catalytic performance of the newly identified enzymes was evaluated for the reduction of various carbonyl compounds, including ketoesters and heterocyclic ketones, from which chiral alcohol products that are valuable intermediates for the synthesis of important pharmaceuticals are obtained. All the enzymes exhibited catalytic activity towards ethyl benzoylformate. In addition, CPR-C2 even showed activity towards 1-benzyl-3-pyrrolidinone. Moreover, the enzymes were capable of catalyzing highly stereospecific reduction of the tested substrates to their corresponding chiral alcohols in high optical purity (>99\%e.e.). Based on their catalytic performance and excellent stereoselectivity, the newly 


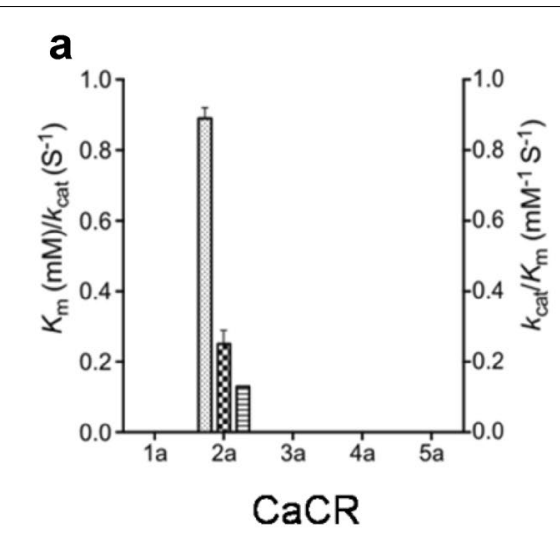

\section{b}

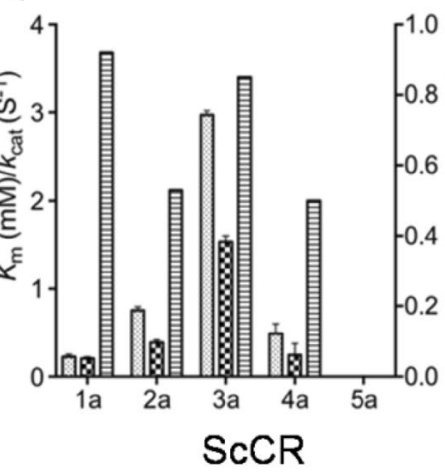

C
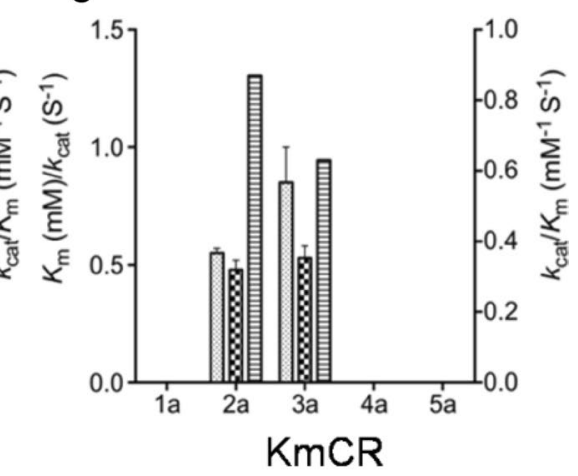

d

$\mathbf{e}$

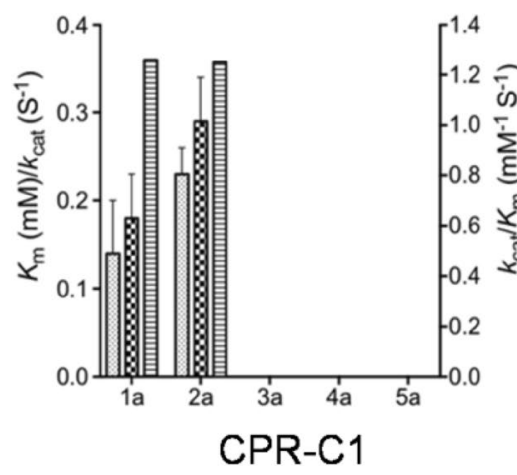

Fig. 4 Apparent kinetic parameters of the enzymes, including a CaCR, b ScCR, c KmCR, d CPR-C1, and e CPR-C2 in reduction of the carbonyl substrates. The primary $Y$-axis " $K_{m}(m M) / k_{c y t}\left(s^{-1}\right)^{\prime \prime}$ means " $K_{m}(m M)$ or $k_{c y t}\left(s^{-1}\right)^{\prime}$. Enzymatic activities were assayed at various concentrations of each substrate $(0.05-4 \mathrm{mM})$ with NADPH at saturated concentrations. Tetrahydrofuran ( $1 \% \mathrm{v} / \mathrm{v})$ was used as the cosolvent for dissolution of carbonyl substrates

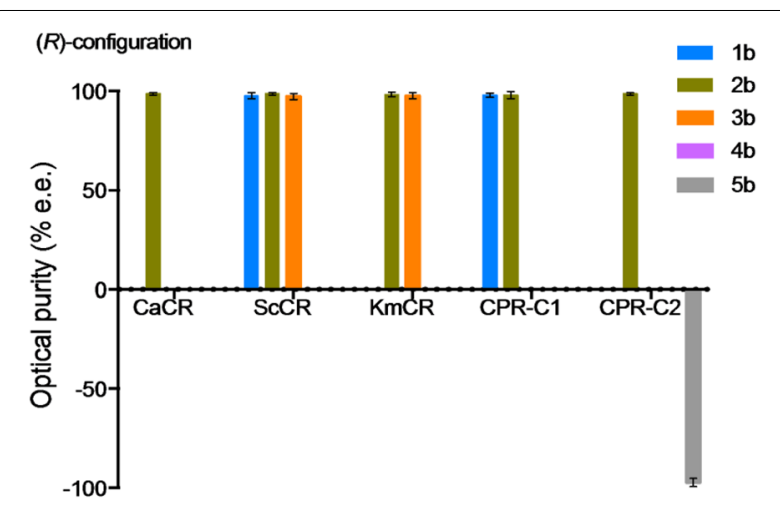

(S)-configuration

Fig. 5 Enantioselectivity of recombinant enzymes towards the carbonyl substrates. The configurations of the products, including (1b) methyl 2-hydroxy-2-phenylacetate, (2b) ethyl mandelate, (3b) ethyl 2-hydroxy-4-phenylbutyrate, (4b)

3-hydroxy-3-phenylpropionate, and (5b) N-benzyl-3-pyrrolidinol were analyzed as described in Table 2 identified AKRs may be useful in preparation of important enantiopure alcohols.

\section{Additional file}

Additional file 1. Additional table and figures.

\section{Authors' contributions}

$\mathrm{YN}, \mathrm{XM}$, and $\mathrm{YX}$ designed the experiments; $\mathrm{CL}$ performed the experiments; $C L$ and $Y N$ wrote this manuscript. All authors read and approved the final manuscript.

\section{Author details}

${ }^{1}$ School of Biotechnology and Key Laboratory of Industrial Biotechnology of Ministry of Education, Jiangnan University, 1800 Lihu Road, Wuxi 214122, China. ${ }^{2}$ State Key Laboratory of Food Science and Technology, Jiangnan University, 1800 Lihu Road, Wuxi 214122, China.

\section{Acknowledgements}

We would like to thank Editage (http://www.editage.cn) for English language editing. 


\section{Competing interests}

The authors declare that they have no competing interests.

\section{Availability of data and materials}

All data generated or analyzed during this study are included in this article.

\section{Consent for publication}

All authors have read and approved to submit it to bioresources and bioprocessing. There is no conflict of interest of any author in relation to the submission.

\section{Ethics approval and consent to participate}

Not applicable.

\section{Funding}

Financial supports from the National Natural Science Foundation of China (21336009, 21676120), the Natural Science Foundation of Jiangsu Province (BK20151124), the 111 Project (111-2-06), the High-end Foreign Experts Recruitment Program (GDT20183200136), the Program for Advanced Talents within Six Industries of Jiangsu Province (2015-NY-007), the National Program for Support of Top-Notch Young Professionals, the Fundamental Research Funds for the Central Universities (JUSRP51504), the Project Funded by the Priority Academic Program Development of Jiangsu Higher Education Institutions, the Jiangsu province "Collaborative Innovation Center for Advanced Industrial Fermentation" industry development program, and the National First-Class Discipline Program of Light Industry Technology and Engineering (LITE2018-09) are greatly appreciated.

\section{Publisher's Note}

Springer Nature remains neutral with regard to jurisdictional claims in published maps and institutional affiliations.

Received: 10 April 2018 Accepted: 5 July 2018

Published online: 16 July 2018

\section{References}

Athanasiou N, Smallridge AJ, Trewhella MA (2001) Baker's yeast mediated reduction of $\beta$-keto esters and $\beta$-keto amides in an organic solvent system. J Mol Catal B-Enzym 11:893-896

de Lacerda PSB, Ribeiro JB, Leite SGF, Ferrara MA, Coelho RB, Bon EPS, da Silva Lima EL, Antunes OAC (2006) Microbial reduction of ethyl 2-oxo4-phenylbutyrate. Searching for $R$-enantioselectivity. New access to the enalapril like ACE inhibitors. Tetrahedron Asymmetry 17:1186-1188

Engelking H, Pfaller R, Wich G, Weuster-Botz D (2006) Reaction engineering studies on $\beta$-ketoester reductions with whole cells of recombinant Saccharomyces cerevisiae. Enzyme Microb Technol 38:536-544
Guo JL, Mu XQ, Xu Y (2010) Integration of newly isolated biocatalyst and resinbased in situ product removal technique for the asymmetric synthesis of (R)-methyl mandelate. Bioprocess Biosyst Eng 33:797-804

Guo RY, Nie Y, Mu XQ, Xu Y, Xiao R (2014) Genomic mining-based identification of novel stereospecific aldo-keto reductases toolbox from Candida parapsilosis for highly enantioselective reduction of carbonyl compounds. J Mol Catal B-Enzym 105:66-73

Jez JM, Bennett MJ, Schlegel BP, Lewis M, Penning TM (1997) Comparative anatomy of the aldo-keto reductase superfamily. Biochem J 326:625-636

Kaluzna IA, Matsuda T, Sewell AK, Stewart JD (2004) Systematic investigation of Saccharomyces cerevisiae enzymes catalyzing carbonyl reductions. J Am Chem Soc 126:12827-12832

Kasprzak J, Rauter M, Denter S, Becker K, Baronian K, Bode R, Schauer F, Piontek M, Vorbrodt H-M, Kunze G (2016) Synthesis of ethyl (R)-mandelate using recombinant Carboxydothermus hydrogenoformans alcohol dehydrogenase produced by two yeast species. J Mol Catal B-Enzym 133:176-186

Kizaki N, Yasohara Y, Nagashima N, Hasegawa J (2008) Characterization of novel alcohol dehydrogenase of Devosia riboflavina involved in stereoselective reduction of 3-pyrrolidinone derivatives. J Mol Catal B-Enzym 51:73-80

Ma YH, Lv DQ, Zhou S, Lai DY, Chen ZM (2013) Characterization of an aldoketo reductase from Thermotoga maritima with high thermostability and a broad substrate spectrum. Biotechnol Lett 35:757-762

Nie Y, Xiao R, Xu Y, Montelione GT (2011) Novel anti-Prelog stereospecific carbonyl reductases from Candida parapsilosis for asymmetric reduction of prochiral ketones. Org Biomol Chem 9:4070-4078

Nikaido T, Matsuyama A, Ito M, Kobayashi Y, Oonishi H (1992) Stereospecific reduction of 2-oxo-4-phenylbutanoate to ( $R$ )-2-hydroxy-4-phenylbutanoate with microbial cells. Biosci Biotechnol Biochem 56:2066-2067

Ou Z, Chen X, Ying G, Shi H, Sun X (2011) Continuous preparation of (S)3-hydroxy-3-phenylpropionate by asymmetric reduction of 3-oxo-3-phenylpropionic acid ethyl ester with Saccharomyces cerevisiae CGMCC No. 2266 in a membrane reactor. Biotechnol Bioprocess Eng 16:320-326

Schoemaker HE, Mink D, Wubbolts MG (2003) Dispelling the myths-biocatalysis in industrial synthesis. Science 299:1694-1697

Wang LJ, Li CX, Ni Y, Zhang J, Liu X, Xu JH (2011) Highly efficient synthesis of chiral alcohols with a novel NADH-dependent reductase from Streptomyces coelicolor. Bioresour Technol 102:7023-7028

Wang YJ, Liu XQ, Luo X, Liu ZQ, Zheng YG (2015) Cloning, expression and enzymatic characterization of an aldo-keto reductase from Candida albicans XP1463. J Mol Catal B-Enzym 122:44-50

Yamada-Onodera K, Fukui M, Tani Y (2007) Purification and characterization of alcohol dehydrogenase reducing N-benzyl-3-pyrrolidinone from Geotrichum capitatum. J Biosci Bioeng 103:174-178

Zhao M, Gao L, Zhang L, Bai Y, Chen L, Yu M, Cheng F, Sun J, Wang Z, Ying X (2017) Asymmetric reduction of ketopantolactone using a strictly $(R)$ stereoselective carbonyl reductase through efficient NADPH regeneration and the substrate constant-feeding strategy. Biotechnol Lett 39:1741-1746

\section{Submit your manuscript to a SpringerOpen ${ }^{\circ}$ journal and benefit from:}

- Convenient online submission

- Rigorous peer review

- Open access: articles freely available online

- High visibility within the field

Retaining the copyright to your article

Submit your next manuscript at springeropen.com 